\title{
A MUDANÇA EM TERAPIA FAMILIAR: CONSTRUINDO AGENCIAMENTO
}

\author{
THERAPEUTIC CHANGE IN FAMILY THERAPY: CONSTRUCTING AGENCY
}

BERENICE ARAÚJO DANTAS DE BIAGI

Universidade Federal de Uberlândia, MG, Brasil

\section{EMERSON FERNANDO} RASERA

Universidade Federal de Uberlândia, MG, Brasil
Recebido em: 27/09/2017 Aprovado em: 22/01/2018
RESUMO: Este artigo visa compreender o processo de produção de sentidos sobre a mudança em terapia familiar sob a perspectiva construcionista social. A análise do processo terapêutico de uma família apontou que a construção conversacional da mudança terapêutica foi marcada pelo deslocamento do discurso inicial do problema de saúde da mãe, oriundo do trabalho, para 0 discurso do agenciamento com o cuidado da vida. Tal construção foi analisada em relação a três aspectos centrais: (a) a desconstrução do sentido do trabalho; (b) a redefinição da relação mãe-filha; (c) a reconstrução da vida. A análise permitiu ainda compreender um importante processo subjacente, 0 agenciamento como forma de promover a mudança terapêutica em terapia familiar. Concluímos que a postura aberta, ativa e engajada da terapeuta com o fluxo da conversa favoreceu a emergência desses sentidos de mudança.

PALAVRAS-CHAVE: terapia familiar; mudança terapêutica; produção de sentidos; agenciamento; poética social.
ABSTRACT: This article aims to understand the meanings making process about change in family therapy under the constructionist perspective. The analysis of the therapeutic process of a family pointed out that the conversational construction of the therapeutic change was marked by shifting the discourse from the initial health problem of the mother which arose from her work to a discourse of managing care in life. Such construction was analyzed in relation to three key aspects: (a) the deconstruction of the meaning of work, (b) the redefinition of the mother-daughter relationship, and (c) reconstruction of life. The analysis allowed further comprise an important process underlying, the agency as way to promote therapeutic change in family therapy. We concluded that the open, active and engaged stance of the therapist in the flow of the conversation favored the emergence of these meanings of change.

KEYWORDS: Family therapy; therapeutic change; meaning production; agency; social poetics.

\section{INTRODUÇÃO}

A história da Terapia Familiar é marcada por mudanças paradigmáticas que questionam os alicerces conceituais da mesma, principalmente as questões voltadas para a postura do terapeuta e da mudança. $\mathrm{O}$ registro teórico das articulações do Construcionismo Social com a Terapia Familiar é encontrado em vários autores (Boczkowski, 1995; Gergen, 1993; Grandesso, 2000, 2009; Guanaes, 2006; McNamee \& Gergen, 1998; Rapizo, 1998; Rasera \& Guanaes, 2010; Rasera \& Japur, 2004, 2007). O pressuposto conceitual deste modelo é que o problema se encontra na descrição do problema, e que, consequentemente, a mudança consiste em descrever os problemas de maneiras distintas, gerando diferentes acordos e consequências. O foco não é a família, subsistemas ou indivíduo, mas as histórias 
encaixadas no espaço virtual da conversação entre as pessoas.

Em uma perspectiva construcionista, a compreensão da mudança não pressupõe um estudo composto por estágios evolutivos, referidos a partir de categorias gerais e alheias ao relato do cliente. Ela apresenta um discurso diferente a respeito da mudança, considerada menos em termos de categorias objetivas, estabilidade, e mais em termos dos processos discursivos e relacionais locais, possibilitando, assim, a construção dinâmica de sentidos de mundo, de problemas e de si. Segundo Guanaes (2006), pensar mudança pressupõe "reconhecer os discursos sobre ela que sustentam as práticas clínicas" (p. 67), bem como as expectativas do cliente a respeito da terapia. Portanto, a mudança está entrelaçada pelo uso da linguagem e constitui-se como uma prática discursiva, uma construção social produto dos relacionamentos pessoais, situada em contextos e no tempo.

No construcionismo social, a mudança é inerente ao diálogo, pois as pessoas estão sempre mudando à medida em que participam de diferentes diálogos e apresentam diferentes descrições de mundo, de problemas e de si nos diferentes contextos. Estar em diálogo pressupõe abertura à influência do outro e à participação conjunta na produção de sentidos. Dito isso, a mudança só pode ser avaliada a partir dos discursos construídos sobre ela e nos contextos relacionais nos quais são produzidos e, não, como uma aquisição estável, individual e interna como postulam algumas terapias modernas. Portanto, a terapia com foco na conversação visa a busca de sentidos de mudança na narrativa do cliente, quanto ao problema e de si, com ênfase nas especificidades das descrições de mudança, bem como na multiplicidade de descrições possíveis sobre ela (Guanaes, 2006).

A terapia como prática conversacional tem o diálogo como generativo e transformador, e os participantes são envolvidos ativamente no processo de coconstrução da mudança. A função do terapeuta é a de facilitador e criador de contextos propícios, mas é o cliente quem acessa, elabora e produz suas competências singulares (Grandesso, 2000).

Nesta perspectiva, a terapia é uma conversação terapêutica, um diálogo, um "falar com" que implica um processo de "estar nisso juntos", em que terapeuta e cliente se comprometem por meio do diálogo, na exploração dos temas imediatos (problema) e no codesenvolvimento de alguma "novidade", isto é, de significados, realidades ou narrativas modificadas ou novas. A novidade se desenvolve continuamente, apontando a dissolução do problema e a cultivar uma nova percepção do cliente quanto à sua capacidade pessoal e sua liberdade. Desta forma, entende-se que os problemas não são resolvidos, mas sim dissolvidos na linguagem, a partir de uma modificação na compreensão do problema; o mesmo deixa de ser sentido como tal e pode ser dissolvido por meio de ações, ou seja, como uma consequência natural do diálogo (Andersen, 2001).

Mudar é contar e recontar histórias que resultam em novas autodescrições; novos sentidos são concedidos aos acontecimentos presentes, passados e futuros imagináveis. A mudança consiste no desenvolvimento de novos selves. Portanto, a capacidade de mudar repousa na habilidade das pessoas estarem abertas ao diálogo e, assim, criar e desenvolver realidades que têm significado para elas, em uma ação conjunta de produção de senti-
A mudança em terapia familiar construindo agenciamento Berenice Araújo Dantas de Biagi Emerson Fernando Rasera 
dos imprevisíveis e não intencionais (Anderson, 2009).

Em uma visão construcionista, somos coautores das identidades que construímos narrativamente, pois "somos tantos selves, tantos si mesmos potenciais quanto aqueles que estão contidos nas conversações dos narradores criativos" (Goolishian \& Anderson, 1996, p. 193). O termo self narrativo usado por Gergen (1996) diz respeito às explicações e narrativas que as pessoas desenvolvem para referirem a si mesmas e às experiências vividas, em que a organização narrativa disponibiliza inteligibilidades que sustentam as suas histórias e as dos outros.

É na linguagem e por meio dela que uma pessoa constrói um relato do self, ou seja, quem acreditamos ser é uma construção linguística. Sob esse ponto de vista, o self é um self dialógico e a identidade é uma identidade narrativa dialógica. Portanto, o self pode ser descrito de infinitas maneiras, como a manifestação de uma narrativa em andamento. Segundo Anderson (2009):

Não somos mais do que um dos múltiplos autores da narrativa em constante mudança que se torna nosso self, e estamos sempre inseridos nos passados históricos múltiplos locais e universais e nos contextos culturais, sociais e políticos da confecção de nossas narrativas. (pp. 180-181) 2008, 2010), refere-se especialmente a um tipo de relacionamento cuja ênfase recai nas respostas corporificadas espontâneas das pessoas umas as outras e ao mundo ao seu redor.

Sendo, portanto, parte de conversas dialógicas, a responsividade propicia um entendimento da qualidade da relação eu-outro. para a diversidade, libertando-se do aprisionamento das posições fechadas em que a pessoa se coloca e que nada faz diferença.

O terapeuta, ao promover um certo tipo de diálogo, favorece a geração de novos sentidos e a construção de narrativas abertas a formas alternativas de vida, e em uma atmosfera não avaliativa, dá voz ao cliente quanto às descrições de problemas e de si. Essa atmosfera cria um contexto apropriado para o engajamento de uma relação mutuamente responsiva, atenta aos pequenos detalhes do encontro. Entretanto, é a responsividade ${ }^{1}$ do terapeuta ao cliente que garante a abertura às possibilidades inventivas do diálogo no tocante à significação (Guanaes, 2006).

No construcionismo social, o processo de produção de sentidos de mudança na relação terapêutica pode ser descrito pelo que Shotter e Katz (1996, 1998) denominam como Poética Social. Ela investiga o espaço relacional e dá visibilidade aos processos discursivos de produção de sentidos. Sua ênfase recai especialmente nas respostas corporificadas espontâneas das pessoas umas as outras e ao mundo ao seu redor. Este termo deriva do grego poíesis e significa dar forma a algo ou a alguma coisa. Nesse sentido, é focada na compreensão das formas especiais de diálogo que se desenvolvem no contexto terapêutico, descrevendo alguns modos de fala e de interação que criam aberturas para a construção conversacional da mudança.

A contribuição da Poética Social para o estudo da relação terapêutica permite compreender os momentos de criação de sentidos por meio de uma relação dialógica em que terapeuta e cliente/família engajam-se em uma conversa orientada pela busca de diferenças, de conexões que possibi- 
litam a emergência de novidade, ou seja, do "sentido que vem dar forma a algo ainda vivido como sem possibilidade de expressão - geralmente relacionado ao problema que motivou a busca de terapia" (Rasera \& Guanaes, 2010, p. 316). Ajuda-o, assim, a dar forma e sentido a aspectos de sua vida ainda não significados, auxiliando-o na construção de novas possibilidades de coordenar suas relações com o mundo e com as pessoas. Esse tipo especial de interação acontece em momentos significativos, usualmente vividos pelos envolvidos no processo dialógico como "momentos marcantes" (Cunlife, 2002; Shotter, 1998).

Nesta perspectiva, o sentido é uma ação conjunta, não se localiza dentro da cabeça das pessoas, mas no espaço onde acontecem os diálogos transformativos, na fronteira entre as margens. Segundo McNamee (1996), nos momentos de conflito, ao invés de investigarmos a respeito dos significados atribuídos a determinadas ações pelos participantes, devemos explorar "as redes relacionais mais amplas que dão significação às ações em curso" (p. 16).

Desta forma, pretendemos demonstrar uma inteligibilidade poética em Terapia Familiar a qual dá visibilidade às realidades sociais coconstruídas na fronteira do espaço relacional. Podemos, assim, contribuir com um entendimento sobre mudança terapêutica a partir da captura dos momentos marcantes do processo terapêutico.

Dada essa motivação teórico-metodológica, o objetivo do presente estudo consiste em compreender o processo de produção de sentidos sobre a mudança terapêutica em Terapia Familiar. Buscamos especificamente: (a) identificar momentos marcantes do processo terapêutico; (b) articulá-los a uma narrativa de mudança da família.

\section{MÉTODO}

\section{Contexto e participantes}

Esta pesquisa se desenvolveu em um serviço de saúde de uma universidade pública e o recrutamento dos participantes aconteceu conforme o protocolo institucional. O caso estudado decorreu de um encaminhamento médico para atendimento em terapia familiar. Na ocasião, fez-se à família o convite para participar da pesquisa, colocando-a a par dos objetivos e métodos a serem utilizados, obtendo, assim, o seu consentimento com assinatura do Termo de Consentimento Livre e Esclarecido.

Foi analisado um atendimento em terapia familiar de curta duração, em 09 sessões semanais de $1 \mathrm{~h} 30 \mathrm{~min}$. O motivo que nos levou a eleger essa família para analisarmos deveu-se a vários fatores, como: satisfação da família com as mudanças ocorridas; descrições de aprendizagem no processo terapêutico; e por se tratar de um atendimento exitoso em que se construíram realidades sociais a partir do agenciamento da família. Entendemos por "agenciamento" uma perspectiva conversacional em que a pessoa se refere sobre si mesma como tendo autoridade e competência para plena e responsavelmente ter um papel central nos cuidados com a vida. Ser agente é tanto um recurso como um produto dos aspectos inventivos e criativos da linguagem e da narrativa (Anderson, 1996).

$\mathrm{O}$ núcleo familiar que participou da pesquisa era constituído pela mãe, Marina (46 anos), solteira, educadora, e a filha Karen (13 anos), estudante. Os atendimentos foram realizados pela primeira autora deste estudo e tiveram como objetivo: (a) criar um contexto conversacional propício à geração de novos sentidos; (b) identificar e explo- 
rar as narrativas da família construídas sobre o problema que a afligia; (c) desenvolver, por meio do diálogo, novos significados, narrativas e histórias em que novas autodescrições pudessem surgir.

A postura da terapeuta foi pautada pela posição filosófica proposta por Anderson (2009) que pressupõe uma atitude respeitosa, reflexiva e compartilhada, em que o terapeuta como observador participante situa-se numa posição igualitária e não hierárquica na construção da realidade terapêutica e, como facilitador participante, cria e sustenta conversações dialógicas numa postura de não saber, que presume: confiar e acreditar, fazer perguntas conversacionais ${ }^{2}$, ouvir e responder, manter a coerência, estar em sincronia e honrar a história do cliente. Esta posição é marcada pela multiparcialidade, em que todas as visões presentes são consideradas no sistema terapêutico (Rasera \& Japur, 2007).

\section{Construção e análise do corpus}

A constituição do corpus da pesquisa se deu com a transcrição das sessões áudio-gravadas. O corpus foi analisado a partir das propostas construcionistas, tendo como método de investigação a poética social de Shotter (Cunliffe, 2002; Shotter, 1998). A análise da pesquisa se deu da seguinte forma: (a) leitura aprofundada das sessões transcritas; (b) identificação de momentos marcantes do processo terapêutico, tais como descritos e nomeados pela família e/ou pela terapeuta; (c) análise descritiva dos momentos marcantes, identificando seu contexto de emergência e o intercâmbio entre a família e a terapeuta; (d) articulação dos sentidos produzidos sobre os diferentes momentos mar- cantes, costurando narrativas de mudança terapêutica.

\section{MARINA E KAREN: CONSTRUINDO AGENCIAMENTO}

Marina foi encaminhada pela cunhada Nelma, a qual estava preocupada com a saúde da mesma. A queixa inicial que motivou a procura de terapia se referia ao fato de Marina estar "muito nervosa", segundo palavras da mesma na triagem, sentir cansaço, formigamento do lado direito da cabeça que refletia por todo o lado direito do corpo, insônia e diarreia após se alimentar. Marina relacionava tudo isso à sobrecarga de trabalho que realizava como educadora de crianças em uma escola, onde tinha dificuldade em compartilhar com a equipe e direção as questões estressantes que enfrentava sozinha no trabalho.

Consideramos como eixo do processo de construção de sentidos de mudança nessa família o deslocamento do discurso do problema de saúde da mãe oriundo do trabalho para o discurso do agenciamento com o cuidado da vida. Este deslocamento foi analisado em relação a três aspectos centrais: (a) a desconstrução do sentido do trabalho; (b) a redefinição da relação mãe-filha; (c) a reconstrução da vida.

\section{A desconstrução do sentido do trabalho}

Alguns momentos marcantes no processo terapêutico com essa família se articularam em torno do deslocamento do discurso do problema inicial da sobrecarga de trabalho para o agenciamento com o cuidado da vida. Esse processo conversacional permitiu uma redefinição do problema a partir 
do agenciamento constituído no reconhecimento da importância do cuidado com a vida e dos próprios limites, bem como das potencialidades dos membros da família. Entre os diversos momentos que marcaram esse processo destacaria aquele referente à compreensão do discurso dominante sobre o trabalho nesta família, com seus efeitos no processo de adoecimento.

Um momento importante do processo de desconstrução do sentido do trabalho diz respeito ao reconhecimento do próprio valor. Nesse reconhecimento, identificamos um elemento significativo no processo de construção do agenciamento de Marina. Trata-se de um trecho de conversa em que ela apresenta sua visão transformada em relação aos seus direitos e deveres, demonstrando certo empoderamento que a permitiu se sentir legitimada a estabelecer uma relação de trabalho marcada pelo senso de justiça.

$\mathrm{Na}$ última sessão, Marina afirma que "começar a ver um pouco" o seu valor fez uma diferença ao voltar às aulas na escola. A partir do momento em que se apropria dessa descrição, Marina identifica uma ação correspondente em sua rotina de trabalho ao não aceitar um convite de uma professora para trabalhar junto com ela como educadora. Ela conta em vários momentos que, além de se sobrecarregar com suas atividades e daqueles que, segundo ela, "empurravam serviço”, costumava levar serviço para casa, como confeccionar fantasias para as crianças para a comemoração das datas festivas, inclusive causando problemas pela falta de reconhecimento dos colegas do seu direito em compensar as horas trabalhadas em casa costurando.

Terapeuta: (...) Então, Marina, como você se descreve hoje?
Marina: Hoje, assim... é porque é... eu acho assim que... eu tô começando, começando a ver um pouco do meu valor que antes eu não tava nem vendo....

Terapeuta: Humm...

Marina: Eu tava achando que eu... tudo que eu fazia pros outros era pouco ainda (...) Eu tava sempre em divida com as pessoas. Hoje... hoje de acordo com as nossas conversas parece que eu tô assim... deixando um pouquinho mais também pro presente: "Opa eu também tô aqui, eu também mereço alguma coisa”. Tá... tá devagarzinho... mas tô melhorando, talvez assim, um pouquinho mais...

Terapeuta: Essa descrição que você falou. Ela te ajuda? Em... te aju...

Marina: Ajuda porque, por exemplo, é... por exemplo igual ontem. Ontem não, hoje. É... tem uma amiga nossa lá da escola (inaudível). Ela, ela vai pegar uma sala com 12 crianças do anexo, de três anos. Aí, eles vão colocar com ela um rapaz, um cidadão que não gosta muito de trabalhar. Aí ela tá doidinha que eu vou trabalhar com ela. Mas como eu já trabalhei com ela, eu sei que ela é daquelas assim que... Ela sai da sala, larga as crianças sozinha pra gente tomar conta. E... ela é assim, ela não gosta de ajuda, ela gosta que a gente trabalha pra ela. Aí eu consegui falar que eu não queria. Falei, não.

Consideramos este momento como marcante na conversa terapêutica, pois Marina apresenta uma descrição de si mesma com uma visão transformada em relação à sua posição anteriormente apresentada na construção do problema ao expressar a sua vontade de
A mudança em terapia familiar construindo agenciamento Berenice Araújo Dantas de Biagi Emerson Fernando Rasera 
viver de forma a serem considerados seus direitos e deveres e a questão da justiça nessa relação. Essa redefinição de um jeito de viver é um aprendizado do processo terapêutico construído relacionalmente.

Nessa interação, percebemos a construção do agenciamento de Marina, que afirma começar a ver o seu valor, criando, assim, a possibilidade de redefinir sua relação com as pessoas, até então marcada pela dedicação, o servir, com o preço de esquecer-se de si e sobrecarregar-se no trabalho e nas relações familiares. A correspondência disso na ação é o fato de ela ter conseguido dizer "não". Esta instância foi construída conjuntamente pela terapeuta-família, pois o tema sobre a forma como Marina se coloca nas relações foi recorrente em quase todas as sessões.

\section{A redefinição da relação mãe-filha}

Outro processo conversacional que relacionamos com o deslocamento do discurso do problema de saúde da mãe oriundo do trabalho para o discurso do agenciamento com o cuidado da vida diz respeito à mudança dessa família a partir da terapia que implicou uma transformação na relação mãe-filha.

Um dos momentos interativos de redefinição da relação mãe-filha diz respeito ao reconhecimento do direito de "ouvir" as próprias vontades, identificado em uma abertura no diálogo para o reconhecimento de possibilidades inventivas de vida consonantes com um senso de agenciamento. A seguir apresentamos o trecho que descreve a construção dessa mudança.

$\mathrm{Na}$ última sessão, Marina apresenta um relato referente à avaliação do processo terapêutico, no qual ela anuncia a decisão que tomou diante de sua família mais ampla para poder repensar e reorganizar melhor a sua vida. Por várias vezes, enfatizou a prioridade que daria à "vontade" dela e da filha neste empreendimento. Esta conversa terapêutica inaugura uma narrativa que se anuncia com uma possibilidade de vida ainda não expressa.

Marina: (...) Minha mãe falou assim, né? "Ah domingo a gente vai na casa da amiga que teve nenê e já vai na casa do vô da Karen". Aí eu falei: "Mãe eu não quero ir lá, não amanhã". Não sei nem como é que eu falei. Ela falou: "Uai então tá, só pensei". "Mas eu não quero. Não, eu num tô com vontade de ir lá agora. Karen cê quer ir lá"? "Também não tô com vontade."

Terapeuta: Isso não existia?

Marina: Não. "Vamo?" "Nada". Precisa disso... A gente agora tá mostrando a nossa vontade. E antes da terapia não tinha isso.

Terapeuta: Antes não tinha vontade?

Marina: Não, a gente pensava que a gente era obrigada, porque a gente tava sempre precisando demais dos outros... E a gente tinha que fazer todas as vontades, prá gente não ficar sozinha. Mas eu pensava assim, a Karen eu acho que... Nem pensava em nada. Ela não tinha nem direito de pensar, tadinha...

Terapeuta: (...) É... E agora?

Marina: Eu pensava assim, se eu ficar sozinha ela vai ficar abandonada, pensava assim, se eu morrer de repente ou se eu ficar muito doente e não tiver cultivado a amizade da minha família, ela vai ficar... Sozinha, 
pensava assim, ela vai ficar sozinha pra sempre, mas não é bem assim.

Terapeuta: Você descobriu isso na terapia?

Marina: Foi. Da gente conversar, você foi me mostrando o caminho não é só por um lado, tinha vários caminhos, eu tive um pouquinho num, um pouquinho noutro, podia pegar atalhos.

Terapeuta: Humm. Pensar em vocês...

\section{Marina: $\hat{E}$.}

Esta interação conversacional redefine a relação mãe-filha diante do contexto familiar mais amplo, legitimando as questões que dizem respeito a ambas. E, consequentemente, redefine também as relações com o entorno familiar e social e suas demandas, deixando emergir uma narrativa que contém elementos que contribuem na desconstrução do problema inicialmente apresentado e, ao fazê-lo, acessa novos sentidos com possibilidades de reinvenção da vida.

Consideramos esse momento marcante pela própria carga emocional que envolveu a todos os presentes no sistema terapêutico. Marina, ao expressar o seu medo de morrer e deixar sua filha sozinha e desamparada, parece entender que isso a aprisionou à necessidade de servir a todos. Profere também a intenção de se desvencilhar desse único sentido vivido nas relações familiar e social, e ainda se compromete relacionalmente com a filha, ao incluir as suas vontades nos contextos conversacionais futuros, demonstrando um aprendizado do processo terapêutico. Ao fazer isso, confessa a importância da filha em sua vida e isso as aproxima ainda mais. Imediatamente, tal diálogo disponibiliza possibilida- des de construção de realidades ainda inacessíveis na linguagem, pela abertura de novos sentidos pela vida afora.

\section{A reconstrução da vida}

Um importante processo conversacional relacionado com o deslocamento do discurso do problema de saúde da mãe oriundo do trabalho para o discurso do agenciamento com o cuidado da vida se refere à possibilidade de "reconstrução da vida". Tal processo é marcado por mudanças no modo como a família passou a descrever a solução do problema.

Destacamos um momento interativo que diz respeito a este processo conversacional que denominamos "Construindo o futuro". Esse momento apresenta transformações na linguagem que denotam o entendimento e ampliação de novos sentidos do problema inicialmente apresentado.

A construção referente ao futuro é marcada por uma conversa reflexiva em que Marina questiona o seu jeito de estar no mundo, sempre disponível às demandas alheias. Esta reflexividade viabiliza a dissolução do problema na linguagem, bem como sinaliza abertura quanto a possibilidades de mudanças nas ações, coerentes com um novo sentido, pautadas por um senso de agenciamento.

$\mathrm{Na}$ última sessão, um momento marcante apontado por Marina diz respeito às conversas terapêuticas que a fizeram perceber como lida com as demandas relacionais, tanto da família quanto do trabalho. Tais conversas no processo terapêutico foram recorrentes, permitindo que a queixa inicial fosse redefinida, com o surgimento de novas questões a serem consideradas na resolução do problema. A resolução do problema, por sua vez, passou 
a ser vista com os recursos do próprio sistema familiar, pois a busca de ajuda na terapia foi inicialmente voltada para o tema do adoecimento em si, enaltecendo-se o discurso dos profissionais, os procedimentos médicos, etc. Esse momento marcante amplia possibilidades e alternativas de vida até então não expressas.

Terapeuta: Então, e... (...) Vocês conseguem definir alguns momentos que vocês consideram mais marcantes na terapia? Momentos que vocês acham que marcou? Assunto que a gente conversou?

Marina: É... Eu acho que mais assim. Eu acho que foi assim, é... acho que todos foram importantes. O mais importante que eu achei foi quando a gente começou a falar da nossa convivência dentro de casa. Você falou assim pra mim que eu tomo a decisão pelos outros. Eu não chego assim, eu não espero a pessoa pedir, que eu passo, como diria a minha mãe: "o carro na frente dos boi”. E esperar quando a pessoa sentir a necessidade de pedir, não. Eu vou já fazendo, já resolvendo o problema meu, é... Largo o meu, vou resolver os dos outros.

Terapeuta: Humm.

Marina: Foi assim nessa parte.

Terapeuta: Hum.

Marina: Aí eu parei um pouco pra pensar, pra gente começa a conversar em casa...

Nesta interação, Marina considera a possibilidade de conversar com as pessoas em casa antes de tomar alguma decisão para ajudar alguém e sobre apresentar a sua decisão de não se intrometer na vida delas, pois antes de- seja saber o que é melhor para ela e a filha. Identificamos a utilização do recurso de outras vozes, vindas da mãe, contribuindo como instância reflexiva a ser considerada na solução do problema e construção da mudança.

Esse momento marcante representa a possibilidade de um entendimento - por parte de Marina - de uma vida nova, contando com seus recursos, desvencilhando-se dos problemas das pessoas da família mais ampla e tornando-se, assim, mais leve, com permissão legitimada nas relações familiares e sociais para usufruir um pouco a vida e seguir em frente com a filha.

\section{CONSTRUINDO AGENCIAMENTO: PROCESSOS E REFLEXÕES}

Um importante processo conversacional que marcou a mudança terapêutica desta família foi o deslocamento do discurso do problema de saúde da mãe oriundo do trabalho para o discurso do cuidado da vida. A mudança foi identificada nas trocas conversacionais, nos momentos interativos, na compreensão da complexidade do problema e na abertura no diálogo. Esse processo permitiu o alcance de novos entendimentos, constituindo, assim, novas descrições de si, do outro e do mundo, vislumbrando-se realidades conversacionais sob uma nova premissa, a do agenciamento.

$\mathrm{O}$ senso de agenciamento implica uma postura ativa no processo criativo de ampliação de significados que disponibiliza alternativas de vida. Ele se dá quando novos relatos e autodescrições são adquiridos, os quais possibilitam a recriação da autobiografia. O passado pode ser reescrito e desta reedição emerge a permissão para se seguir em frente, com um senso de li- 
berdade, de esperança, sob a premissa de novos relatos capacitantes, baseado na habilidade de dar formas às suas vidas, mas sem se desligar de suas raízes culturais (Shotter, 1991, 1995).

Em nossa análise, o processo dialógico do agenciamento se deu da seguinte forma: (a) desconstruindo o autoaprisionamento; (b) legitimando-se a partir do outro; (c) reconhecendo as próprias necessidades; (d) construindo alternativas de vida.

A desconstrução do autoaprisionamento diz respeito a uma autodescrição transformada de Marina em relação à narrativa que ela apresentava a respeito da necessidade em ajudar as pessoas. Tal relato é fruto de um diálogo interno, em que questionou a possibilidade de uma ação diferente frente a um pedido de ajuda de um colega de trabalho, e a reflexividade disponibilizou a sua autonomia, com a restituição do direito de escolher atender ou não a um pedido de ajuda alheio. A desconstrução de sentidos aprisionantes se dá nas conversações terapêuticas, que se convertem em indagações do que se pode ver e ouvir nas situações sentidas pelo cliente como problemáticas, nas quais existem muitas outras coisas que podem ser vistas e ouvidas. $\mathrm{E}$ a melhor maneira de alcançar o não visto e o não ouvido é abordar detalhadamente a descrição da situação, posto que, quando se consegue ver e ouvir algo novo, automaticamente uma nova compreensão é alcançada, emergindo, assim, novas ideias de como manejá-las, liberando, dessa forma, tais sentidos aprisionantes (Andersen, 2001).

A legitimação a partir do outro se deu por meio das transformações na relação mãe-filha e o compartilhar questões que antes preocupavam apenas a mãe. Neste sentido, ampliam-se as possibilidades dialógicas com estreitamento dessa relação, dando iní- cio a um processo de entendimento de questões até então negligenciadas pelo fato de se priorizar as necessidades alheias. Segundo Gergen (2007), a transformação da narrativa acontece em um contexto colaborativo, em que os clientes têm a experiência de serem ouvidos, compreendidos em seus pontos de vista e sentimentos, e de sentirem-se aceitos e confirmados. Isto não significa uma aceitação ou confirmação de seus pressupostos. Resulta em uma forma receptiva de indagação que compreende: abertura a diferentes formas de pontuar a experiência, disposição para explorar múltiplas perspectivas e legitimação de sua coexistência. E na medida em que é experimentada pelo outro, pode provocar uma mudança de atitude em relação à experiência, bem como liberar os participantes na terapia de construções limitantes do mundo.

$\mathrm{O}$ reconhecimento das próprias necessidades demarca o momento de mudança de sentido do foco de atenção, pois anteriormente era colocada nas necessidades das relações externas, sem reconhecimento das próprias necessidades. As mudanças apresentadas pela família denotam a restauração do sentido de agenciamento, demonstrado por meio da recuperação de sua competência, com possibilidade de tomar iniciativa por si mesma, considerando-a conforme as necessidades do seu momento de vida. A restauração e o restabelecimento do sentido de agenciamento do cliente se dão concomitante ao desenvolvimento de novas narrativas e, consequentemente, novas intenções coerentes com este sentido. Esta experiência da transformação é libertadora quanto à aquisição de um entendimento da família em poder ser agente de si mesma e, assim, poder expressá-la em mudanças coerentes com essa nova visão do mundo, das pessoas
A mudança em terapia familiar construindo agenciamento Berenice Araújo Dantas de Biagi Emerson Fermando Rasera 
e de si (Anderson, 1996; Goolishian \& Anderson, 1996).

A construção de alternativas de vida refere-se à consciência adquirida nas trocas dialógicas no processo terapêutico, com sinais de abertura para alternativas de vida consonantes com um senso de agenciamento coconstruído na relação terapêutica. Sob esta premissa, Marina se dá conta da possibilidade de tomar o leme da sua própria vida e, com o poder que lhe foi restituído, se apropria da sua autoridade e competência e faz distinções que permeiam futuras escolhas por privilegiar na primeira pessoa suas questões e da filha, contando com seus recursos.

Segundo Shotter (2008), o problema prático moral básico na vida não é o que fazer, mas o que "ser", constituindo assim o problema fundamental do diálogo terapêutico: como abordar outra pessoa de maneira apropriada, orientando-a nesta direção; ou como relacionar-se com as narrativas sobre o que ela "tem sido" no passado, ajudando-a a remodelar e recriar essas narrativas de maneira que lhe permita enfrentar o que "pode ser" no futuro, com esperança e sem medo. A mudança, nesta perspectiva, é inerente ao diálogo, resultando em redescrições da conversação. No contar e recontar histórias, as experiências são liberadas, reconstituindo vivências passadas, presentes e futuras imagináveis. Por meio de relatos capacitantes, restituem-se possibilidades inventivas e ação no mundo (Anderson, 2009; Shotter, 1991).

Os momentos interativos analisados são marcantes quanto à construção e à importância do agenciamento nessa família. De forma colaborativa, a terapeuta e a família se engajaram em um tipo de conversa de desnaturalização de uma narrativa restritiva e dominante quanto a um jeito de estar no mundo que a aprisionava às demandas alheias do seu entorno social. $E$, à medida que novos sentidos de mundo e de si foram compartilhados, emergiram consigo novas maneiras de se perceber, juntamente com suas ações coerentes com o novo sistema de significação.

\section{CONSIDERAÇÕES FINAIS}

Nesse estudo, pudemos analisar como o agenciamento foi produzido como forma de promover a mudança em terapia familiar. $\mathrm{O}$ agenciamento se refere à possibilidade da pessoa tomar e implementar decisões, consiste em buscar autoria, autonomia, narrativas em primeira pessoa. $\mathrm{O}$ agenciamento como opção discursiva se dá dentro de uma perspectiva dialógica, aberto às possibilidades inventivas da linguagem, tornando-se recurso conversacional disponível no trabalho terapêutico no processo de construção da mudança.

A construção de sentidos de mudança foi identificada no deslocamento do discurso inicialmente apresentado como problema do trabalho da mãe para com o cuidado da vida. $\mathrm{O}$ agenciamento foi promovido tanto pelas trocas conversacionais que construíram novas realidades sociais, quanto pela apropriação e legitimação dos discursos de potência e empoderamento, os quais permitiram a família sentir-se capaz de perceber seus próprios limites e possibilidades, "ouvir" suas próprias vontades e poder atendê-las. Tal construção se deu a partir do desvencilhamento e afastamento do sentido dominante na família a respeito de se disponibilizar em atender às necessidades das pessoas, o que custava, na maioria das vezes, o esquecer-se de si. A família precisou se afastar 
dos sentidos apreendidos nos contextos relacionais mais amplos para constituir o seu agenciamento, sentindo-se capaz, potente e autônoma com as interações, produzindo autonomia e fortalecimento da pessoa para a ação no mundo.

Esse estudo do processo de mudança em Terapia Familiar nos ajudou a entender como a conversa produz a mudança. Esse processo deu-se dentro de uma relação dialógica com o seu entorno, em que as histórias nos convidaram responsivamente a conversar de determinado jeito, a falar de determinado assunto, a fazer determinadas perguntas e a agir e a reagir de determinada forma. Entendemos que isso se deu por nos colocarmos, terapeuta-clientes, conectados com o caráter indeterminante, criativo e de improvisação da natureza coletiva dessa agência.

A instância reflexiva da unidade dialógica do encontro terapêutico nos permitiu atentar para o entendimento da desnaturalização de sentidos aprisionantes trazidos para o processo terapêutico a partir da inclusão da linguagem capturada pela responsividade corporificada e pelas múltiplas vozes presentes no diálogo. Tal perspectiva gerou inovações perceptíveis no diálogo de todos envolvidos na pesquisa. Ao término, seguimos em frente, reverberando algumas dessas vozes, ainda vivas e presentes deste relato. Assim, elas se tornam disponíveis socialmente para aqueles que buscam o entendimento do poder transformativo da linguagem.

\section{REFERÊNCIAS}

Andersen, T. (2001). Ver y oír, ser visto y ser oído. In S. Friedman (Comp.), El nuevo lenguaje del cambio: la colaboración constructiva en psico- terapia (V. Tirotta, Trad., pp. 201224). Barcelona: Gedisa. (Original publicado em 1993)

Anderson, H. (1996). A reflection on client-professional collaboration. Families, Systems, \& Health, 14, 193-206.

Anderson, H. (2009). Conversação, linguagem e possibilidades: um enfoque pós-moderno da terapia (M. G. Armando, Trad.). São Paulo: Roca. (Original publicado em 1970)

Boczkowski, P. J. (1995). Articulaciones del construccionismo social en terapia familiar sistêmica. Sistemas Familiares, 11(2), 37-47.

Cunliffe, A. L. (2002). Social poetics as management inquiry: a dialogical approach. Journal of Management Inquiry, 11(2), 128-146.

Gergen, K. J. (1993). El movimiento del construccionismo social en la psicología moderna. Sistemas $\mathrm{Hu}$ manos, 9(2), 9-23.

Gergen, K. J. (1996). Realidades y relaciones: aproximaciones a la construcción social. Barcelona: Paidós Ibérica

Gergen, K. J. (2007). Construcionismo social, aportes para el debate y la práctica (A. M. E. Mesa \& S. D. Férrans, Trads.). Bogotá: Universidad de los Andes, Facultad de Ciencias Sociales, Departamento de Psicologia, CESO, Ediciones Uniandes).

Goolishian, H. \& Anderson, H. (1996). Narrativa e self: alguns dilemas pós-modernos da psicoterapia. In D. F. Schnitman (Org.), Novos paradigmas, cultura e subjetividade (J. H. Rodrigues, Trad., pp. 191-203). Porto Alegre: Artes Médicas. (Original publicado em 1994).

Grandesso, M. (2000). Sobre a reconstrução do significado: uma análise epistemológica e hermenêutica da prática clínica. São Paulo: Casa do Psicólogo.
A mudança em terapia familiar: construindo agenciamento Berenice Araújo Dantas de Biagi Emerson Fernando Rasera 
Grandesso, M. (2009). Desenvolvimentos em terapia familiar: das teorias às práticas e das práticas às teorias. In L. C. Osório \& M. E. P. Valle (Orgs.), Manual de terapia familiar (pp.104-118). Porto Alegre: ArtMed.

Guanaes, C. (2006). A construção social da mudança em terapia de grupo: um enfoque construcionista social. São Paulo: Vetor.

McNamee, S. (1996). La construcción relacional del significado. De la cabeza al discurso. Talón de Aquiles, 4, 15-17.

McNamee, S. \& Gergen, K. J. (1998). Relational responsibility: Resources for sustainable dialogue. Thousand Oaks, CA: SagePublications.

Rapizo, R. (1998). Terapia sistêmica de família: da instrução à construção. Rio de Janeiro: Instituto NOOS.

Rasera, E. F. \& Guanaes, C. (2010). Momentos marcantes na construção da mudança em terapia familiar. Psicologia: Teoria e Pesquisa, 26(2), 315-322.

Rasera, E. F. \& Japur, M. (2004). Desafios da aproximação do construcionismo social ao campo da psicoterapia. Estudos de Psicologia, 9(3), 431-439.

Rasera, E. F. \& Japur, M. (2007). Grupo como construção social: aproximações entre construcionismo social e a terapia de grupo. São Paulo: Vetor.

Shotter, J. (1991). Consultant re-authoring: the "making" and "finding" of narrative constructions. $\mathrm{Pa}$ per presented at Houston-Galveston Conference on Narrative and Psychotherapy: New Directions in Theory and Practice, Houston, Texas.

Shotter, J. (1995). A "show" of agency is enough. Theory and Psychology, 5(3), 383-390.
Shotter, J. (1998). Social constructionism and social poetics: Oliver Sacks and the case of Dr. P. In B. M. Bayer \& J. Shotter (Eds.), Reconstructing the psychological subject: bodies, practices and technologies (pp. 33-51). London: Sage.

Shotter, J. (2008). Conversational realities revisited: life, language, body and world (2a ed.). Ohio: Taos Institute Publications. (Original publicado em 1993)

Shotter, J. (2010). Social construction on the edge:'withness'- thinking and embodiment. Ohio: Taos Institute Publications.

Shotter, J. \& Katz, A. M. (1996). Articulating a practice from within the practice itself: establishing formative dialogues by the use of a "social poetics". Concepts and Transformation, 1(2-3), 213-237.

Shotter, J. \& Katz, A. M. (1998). “Living moments" in dialogical exchanges. Human Systems, 9(2), 81-93.

\section{BERENICE ARAÚJO DANTAS DE BIAGI}

Universidade Federal de Uberlândia, MG, Brasil. Graduação em Serviço Social, Terapeuta Familiar, Mestre em Psicologia Aplicada pela Universidade Federal de Uberlândia, docente no Poíesis - Instituto de Terapia Familiar do Triângulo.

E-mail: berenicedebiagi@gmail.com

\section{EMERSON FERNANDO RASERA}

Universidade Federal de Uberlândia, MG, Brasil.

E-mail: emersonrasera@gmail.com 